\title{
Earthquake and Geothermal Energy
}

\author{
Surya Prakash Kapoor ${ }^{1}$, Bhag Chand Chauhan ${ }^{2, *}$ \\ ${ }^{1} 60$, Gagan Vihar Extension, Delhi -110051 India \\ ${ }^{2}$ Department of Physics \& Astronomical Science, School of Physical \& Material Sciences, Central University of Himachal Pradesh, \\ Dharamshala, Kangra -176215 India \\ *Corresponding Author: chauhan@iucaa.ernet.in
}

Copyright (C) 2014 Horizon Research Publishing All rights reserved.

\begin{abstract}
The origin of earthquake has long been recognized as resulting from strike-slip instability of plate tectonics along the fault lines. Several events of earthquake around the globe have happened which cannot be explained by this theory. In this work we investigated the earthquake data along with other observed facts like heat flow profiles etc...of the Indian subcontinent and found a high-quality correlation among the various indicators, like the earthquake events, seismic prone zones, heat flow regions and the geothermal sites. As a consequence, we proposed a hypothesis which can adequately explain all the earthquake events around the globe as well as the overall geo-dynamics. It is basically the geothermal power, which makes plate tectonics to stand still, strike and slip over. The plates are merely a working solid while the driving force is the geothermal energy. The non-utilized accumulated geothermal power shakes the earth along the plate boundaries and also triggers the intra-plate seismicity. In the light of the results reported by the California Energy Commission from the ongoing geothermal power project at the Big Geysers in California, we further propounded that by harnessing the surplus geothermal energy the intensity and risk of the impending earthquakes can be substantially reduced.
\end{abstract}

Keywords Earthquake, Geothermal Energy, Plate Tectonics

Index Terms: Seismology-Earthquake Dynamics

Key Points: 1) Geothermal energy is the root cause of tectonic movements and earthquakes

2) Harnessing geothermal energy can reduce the intensity of earthquakes

\section{Introduction}

Unlike other planets of the solar system, earth is a highly dynamic. Some activity is relentlessly going on in the interior of it. Traversing a journey of hundreds of millions years since its birth the earth has been going through a continuous geological change. As a result the continents on the surface had different shapes and were located in different positions from those we find them today [Edward and Fredrick, 1996]. The heat source inside the earth exerts buoyant pressure towards the surface where it leads to geo-dynamism and geothermal events like spectacular volcanoes, hot-springs, hot dry rocks and fumaroles.

The earthquakes are mainly explained as the movement and deformation of the plate tectonics along the fault lines. The rigid plates on the crust and lithosphere are moving slowly and continuously. Although most of the earthquakes have been found to occur along these fault lines associated with plate boundaries, yet there are certain observations like mid-plate seismicity and hotspots, peaceful fault-lines and deep hypocenter not adequately explained by this theory.

After a detailed investigation of the earthquake events, seismic prone zones, geothermal sites and heat flow data of the Indian subcontinent, we propose a hypothesis for the root cause of earthquake which can successfully explain all of the above unexplained facts and as well as the overall earthquake dynamics. According to this at the root it is the non-utilized buoyant pressure of the geothermal power which sponsors the geo-dynamism, plate movements, and thereby earthquakes along the fault-lines and as well as on the thermally porous and brittle zone of the earth.

In the light of observed figures and facts we further argue that the plate movement can be impeded, and thereby seismic activity can be abated by harnessing the surplus pressure amount of geothermal power as electricity from at least in the identified geothermal sites. In the paper, we presented a number of valid points and facts which associate the earthquake events more likely with the geothermal activity rather than just the plate movements.

The paper is organized as follows: Section 2 details the phenomenon of earthquake and the present understanding of its causes and predictions. In Section 3, we propose our hypothesis with its supporting arguments and observed facts by studying the relevant data of Indian subcontinent. However in Section 4 we discuss the potential benefits of harnessing the geothermal energy. Finally, the discussion and conclusions are summarized in Section 5. 


\section{Earthquake and its Current Understanding}

During the years 1912-15 the German meteorologist and geophysicist Alfred Wegener proposed that about 200 million years ago the earth existed as a supercontinent called 'Pangaea'. Then it began breaking into smaller continents, which drifted slowly and slowly to their present positions. This drift was popularly known as 'Continental Drift'. This idea was supported by evidences, like Fit to Continents, Fossil Evidence, Rock Type and Structural Similarities and Paleoclimatic Evidence etc... By 1968 the concept of continental drift united with another idea of 'Seafloor Spreading' emerged as a more encompassing theory of 'Plate Tectonics' [Edward and Fredrick, 1996]. The theory holds that the outer rigid lithosphere of earth is a spherical layer of about seven major individual segments called 'Plates'. These plates are Euro-Asiatic, African, Antarctic, Indo-Australian, North and South American, and Pacific. Several minor plates are positioned between them. The plates merged, not seamlessly, and the resulting lines across are known as 'Faults'.

As per the theory of plate tectonics the major earthquakes are due to the strike-slip and stress-strain action of the plates along the fault lines i.e. by the friction on the boundaries of the plates moving relative to each other. This is considered to be the main reason that most of the earthquakes have been found to occur along these faults associated with plate boundaries. The rigid plates of the lithosphere are slowly, but nevertheless moving continuously. The lithosphere is a strong brittle layer overlying a weak ductile layer, which gives rise to two forms of deformation: brittle fracture, leading to earthquakes in the upper layer, and aseismic ductile flow in the layer beneath.

In the earthquake the vibration of earth is produced by a rapid release of energy. The energy is released as spherical wave-fronts in all the direction starting from the source, the focus [Edward and Fredrick, 1996]. The source lies deep down inside the earth is called as 'hypocenter' and the corresponding point on the surface is known as 'epicenter'. The waves so generated from the source are known as the seismic waves and the study of these waves is known as 'seismology'.

The majority of earthquakes occur in the depths not exceeding tens of Kilometers. The earthquakes occurring at a depth of less than $70 \mathrm{Kms}$ are known as 'shallow-focus' earthquakes, and those with a focal-depth between 70 and $300 \mathrm{Kms}$ are commonly named as 'mid-focus' or 'intermediate-depth' earthquakes. However, 'the deep-focus' earthquakes may occur at much greater depths (ranging from 300 up to $700 \mathrm{Kms}$ ), and these seismically active areas of subduction are known as 'Wadati-Benioff zones'.

Although this view is correct, yet it is imprecise, and in ways that can lead to serious misunderstandings [Christopher, 1998]. The author of the reference [Christopher, 1998] further illustrates that the earthquakes associated with strength and brittleness of the plates if taken much beyond the generality can lead to serious misinterpretations about earthquake mechanics.

There are certain events which the theory cannot explain clearly:

- The intra-plate seismicity and the hotspots far from plate boundaries

- Earthquake preceded/ followed by volcanic eruption and geothermal event [Editorial: Nature,2013]

- Rare earthquake events along the portion of Gangetic plains near the Himalayan plate boundary

- Hypocenters are $700 \mathrm{Kms}$ beneath the lithosphere [NEIC,2005]

In addition, the current understanding is not capable enough to predict the potential earthquakes because of poor knowledge of earthquake dynamics. The mechanics of the rupture formation in the nucleation zone is not well understood. A number of methods have been developed for predicting the time and place in which earthquakes will occur, but the predictions cannot yet be made even to the level of a specific day or a month.

\section{The Hypothesis}

In the present study, we mainly consider the earthquake data, seismic prone zones, heat flow profile and geothermal activity of the Indian geothermal provinces. In our investigation we found an encouraging correlation among all of these indicators. As a result, we propound that the gamut of earthquake phenomena-seismogenesis and seismic coupling, pre- and post-seismic phenomena, and the relatively weak dependence of earthquakes on strike-slip motion along the fault lines - all are the manifestations of the geothermal energy. It is primarily this power, which fuels the instability and movement of the plates. After penetrating, piercing, puncturing and punching through the surface of earth, it emerges out and enters into open space through the oceanic spreading centers, subduction zones, plate collision areas, volcanoes/ hotspots and hot springs etc. The violent flow and enormous pressure of this power may result in hazardous earthquakes along the plate boundaries and even at the mid part of plates. It may be noted that this hypothesis does not rule out the theory of Plate Tectonics, rather it gives a solid base to the plate movements and entire geodynamics, and explain all the events not being answered by the Plate Tectonics Theory alone.

Historically the earth has cooled since it was formed, yet the decay of radiogenic isotopes and in particular uranium, thorium and potassium, in the interior provides a relentless source of heat. In a recent study by the KamLAND Collaboration [KamLAND Collaboration], the decay of Uranium-238 and Thorium-232 together contribute 20 Terawatts (TW) to earth's heat flux. The decay of Potassium-40 are known to contribute just 4 TW. However, on the basis of simulation studies using supercomputer, J. Marvin Herndon proposed earth's inner core as a nuclear reactor- a source of earth's heat [Marvin, $1993 \& 2007$ ]. The 
earth's internal heat powers all geodynamic processes along with generation of geomagnetic field. Based on available scientific evidence, earth's crust and upper mantle primarily composed of solid rocks. Geologists believe that the decay of radioactive elements in the solid rocks of the mantle and crust must heat up the rocks up to $750-1000{ }^{\circ} \mathrm{C}$ and melt the rocks to form the magma [Edward and Fredrick, 1996]. However, at the center of the planet, the temperature may be up to $6,000{ }^{\circ} \mathrm{C}$ and the pressure could reach $360 \mathrm{GPa}$ [Alfe et al, 1795].

The total heat dissipated from the earth to space has been measured with thermal technique to be $44.2 \mathrm{TW}+-1.0$ at the rate of 87 milli W $/ \mathrm{m}^{2}$ [Pollack et al, 1993]. The energy is being replenished by the self-sustained nuclear fission reactions in the interior. The large heat flow have been found to occur on the plate boundaries; besides the plate margins the high heat flow values occur in areas under tension where the crust is thinner than normal as shown in the Figure 1. The high heat flow values on the continents are from volcanic and tectonically active regions while the highest values in the oceans are found near the area of oceanic ridges. In other words, we can say that on the surface of the earth the phenomena of geothermic and its off-shoot geodynamics go hand in hand with each other at plate boundaries. As per surface observations and geothermal data the high temperature $\left(220{ }^{\circ} \mathrm{C}-350{ }^{\circ} \mathrm{C}\right)$ geothermal resources are located at plate boundaries and low to intermediate temperature $\left(50^{\circ} \mathrm{C}-220{ }^{\circ} \mathrm{C}\right)$ resources are spread in the midst of plates. Heat moves up as the result of an unequal distribution inside the earth. The plate motion is driven by a thermal engine. This movement of lithosphere plates generates earthquakes, volcanic activity and deformation of rock masses into mountains [Edward and Fredrick, 1996]. In other words, the energy widely dispersed in the remaining body of the earth energizes the solid earth, including core and mantle convection, plate motion, mountain building, earthquakes and volcanism.

In this work, we argue that most of the geothermal energy inside the earth escapes as heat and eventually radiates in outer space through the volcanoes, hotspots and hot springs etc..., and a tiny bit of this energy is released as earthquakes, where the pressure is too high and passage to release through is rather tough. The high temperature geothermal resources create earthquakes at plate boundaries whereas low to intermediate temperature geothermal resources fund intra-plate seismicity.

According to a latest study the release of mud could have been a natural response of an earthquake after all [Editorial: Nature, 2013]. This argument also favors the geothermal origin of the earthquakes. In the interior the excess pressure of geothermal power fractures the weak part of the plate boundary and earthquake takes place and the mud starts coming out through the brittle or porous part of the lithosphere, if any. The mud flow or eruption can be quite far from the epicenter. Most of the times it just fractures the plate and no mud comes out, because of no easy channel available. So, earthquake happened there but no mud eruption was recorded.
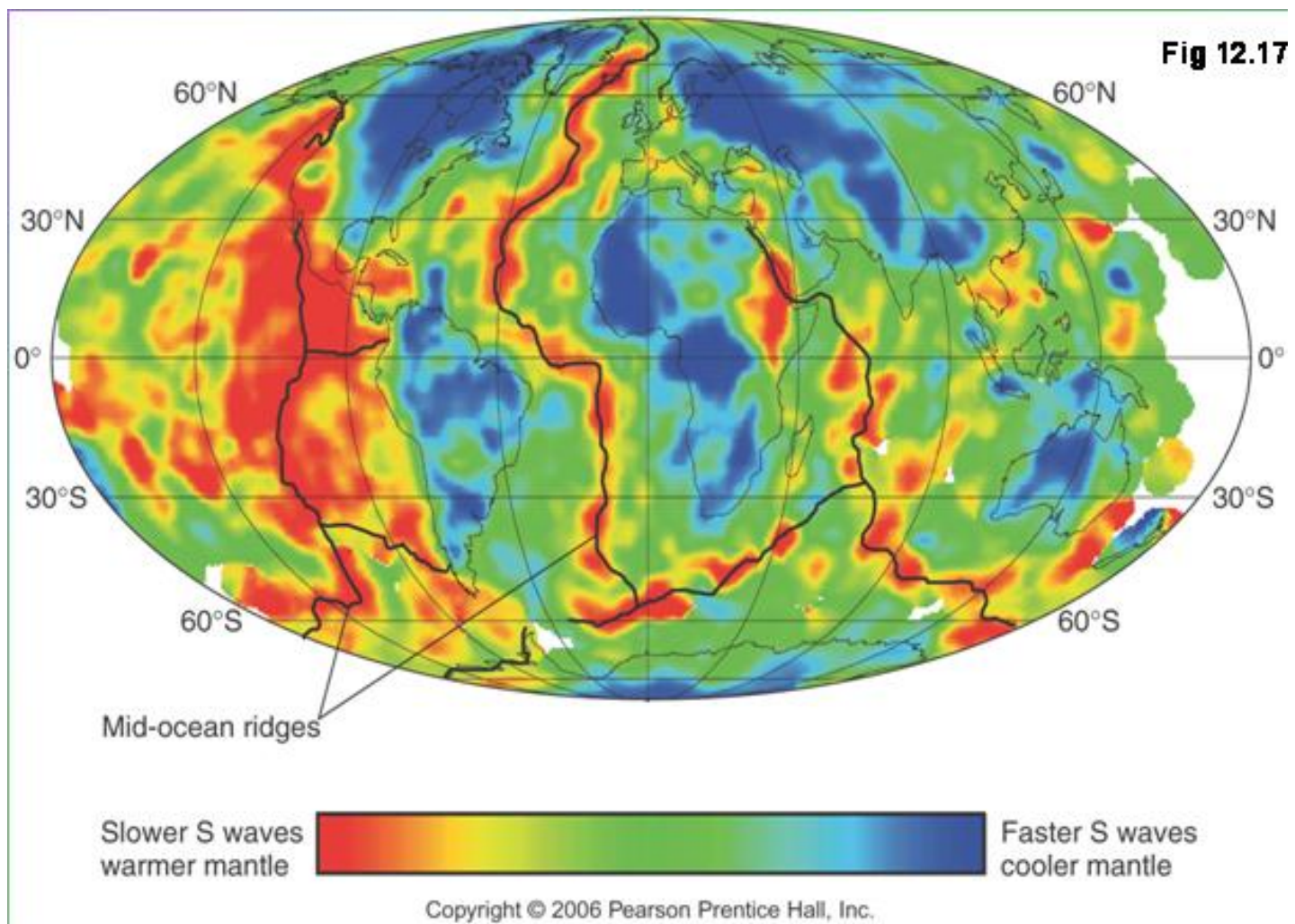

Figure 1. Seismic tomography [Courtesy: Google Images- Pearson Prentice Hall, Inc. 2006] 


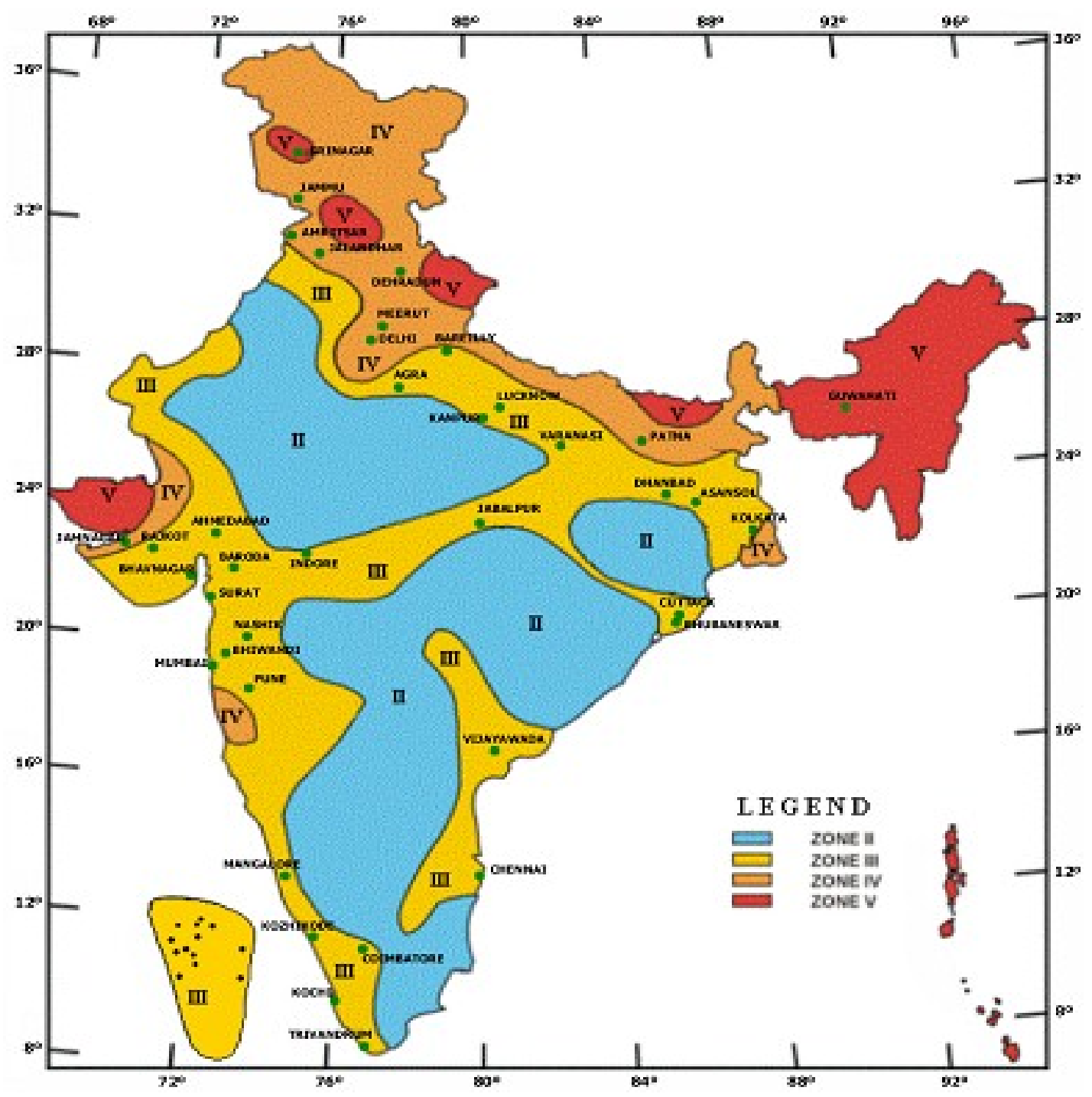

Figure 2. The seismic zone map of India [WCNDM, 2004]

\subsection{Indian Earthquake Zones and Heat Flow Regions}

As per the studies of the Structural Civil Engineers [WCNDM, 2004]: "The intuitive development of the first seismic zone map and of the earthquake resistant features for masonry buildings took place in 1930's and formal teaching and research in earthquake engineering started in late 1950's. The first code of Practice of Bureau of Indian Standards on Earthquake Resistant Design of Structures was published in 1962 (IS 1893-1962). The seismic zoning of the country was brought out in the Code which demarcated a major part of peninsular India as non-seismic. The IS code has undergone several revisions and the latest code (IS 1893-2002) has been divided into five parts, each applicable for different types of structures. The magnitude or intensity of expected earthquake in these regions is based on past data spanning a few hundred years and is not adequately understood. It is generally observed that the Himalayan region has the highest seismic hazard in the country. The Kashmir earthquake (2005), for example, was more intense than the specifications of IS codes for that region. In regions away from the Himalayas, the seismic hazard is even more poorly understood. The Killari earthquake (1993) occurred in a region categorized as seismic Zone-I, which implied low probability of damaging earthquakes. There is an urgent necessity to improve our understanding of the seismic hazard in the country, so that the structures are designed to consider the appropriate intensity of earthquake shaking". The projected Seismic Zone Map of India is shown in the map below:

The region is divided into four (II-V) Zones of various seismic prone areas. The Zone-V (Red) corresponds to the highest scale of earthquake and the Zone II (Blue) shows the region of the lowest seismic probability. While comparing it with the Heat Flow Map [GSI, 1987 \&1991] given below in Figure 3, one can easily validate the fact that the highest heat flow (Zone-I) corroborates with the highest seismic prone area (Zone-V) and the lowest heat flow region (Zone-V), to a good extent, overlaps with the lowest seismicity area (Zone-II). It can be concluded that the amount of surplus geothermal energy accumulated and exploded in the form of 
earthquake is directly proportional to heat flow value of the associated geothermal area. In the Figure 3, the Zone-1 (Red) having highest heat flow value more than 180 milli W/m² spawn the strongest earthquakes most frequently. The Himalayan geothermal area has highest heat flow value 498 milli $\mathrm{W} / \mathrm{m}^{2}$ accounting for almost $60 \%$ share of the aggregate of devastating earthquakes in India.

The Heat Flow Map given by GSI clearly shows the cities like Hyderabad, Bangalore, Lucknow are falling in yellow regions (Zone-V) having heat flow value less than 40 milli $\mathrm{W} / \mathrm{m}^{2}$ the regions are earthquake proof because the heat flow value is so low that it cannot sponsor earthquake. Furthermore, the portion of Gangetic Plains comprising of Kanpur, Allahabad and Varanasi also situated in the lowest heat flow Zone- $\mathrm{V}$, despite in the vicinity of Himalayan plate boundary, has not witnessed any earthquake hazard as per record.

It may be noted that unlike the Heat Flow Map (Figure 3) the Seismic Zone Map (Figure 2) is not based on any concrete scientific foundation rather it is more a hit and trial basis map. We strongly believe that the correlation of the respective zones of Figure 2 and 3 will be better once we get the more accurate one.

\subsection{Indian Geothermal Provinces and Earthquakes}

The geothermal regions in India are divided into seven provinces, namely Himalayas, Sohana, Cambay, West Coast, SONATA, Godavari, and Mahanadi. These seven geothermal provinces are characterized by high heat flow value (78-468 milliW/m $\mathrm{m}^{2}$ ) and thermal gradients (47-100 ${ }^{0} \mathrm{C} / \mathrm{Km}$ ) and discharge about 400 thermal springs within Indian jurisdiction. After the oil crisis in 1970s, the Geological Survey of India conducted reconnoiters on them in collaboration with $\mathrm{UN}$ organization and reported the results in several of their records and special publications [GSI, $1987 \& 1991]$.

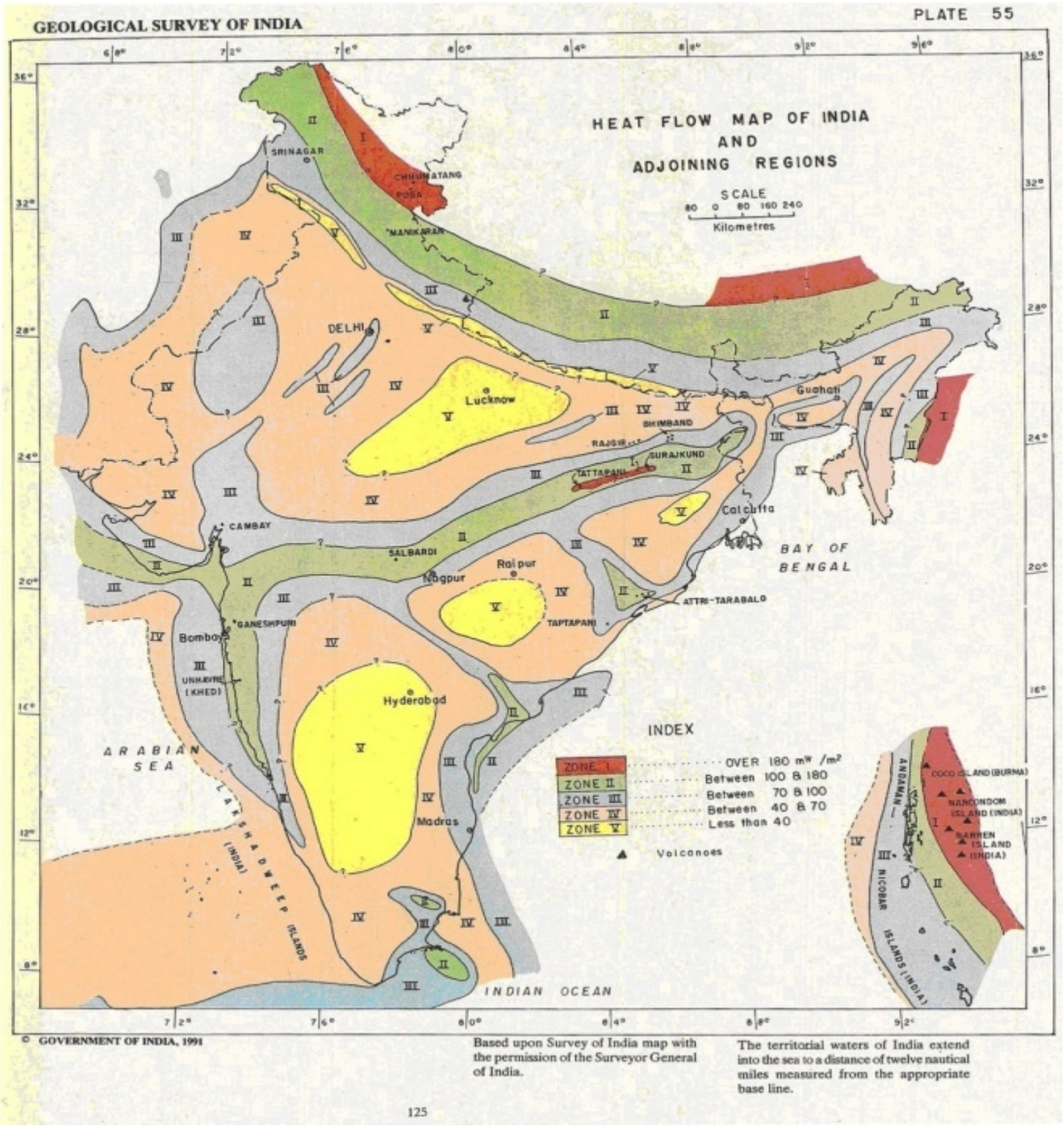

Figure 3. Heat Flow Map of India [GSI, 1987 \&1991] 


\section{SEVEN GEOTHERMAL PROVINCES OF INDIA}
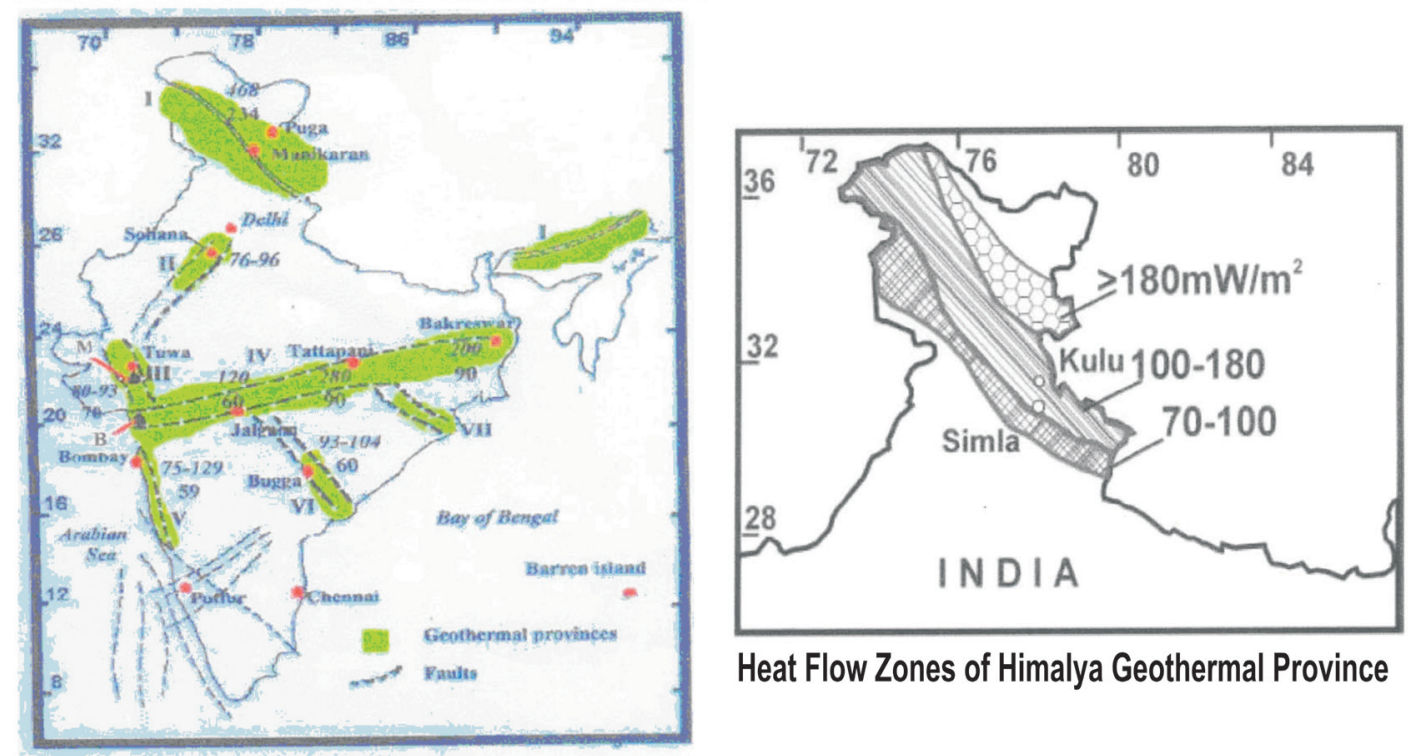

Fig. 1. Map of India showing the geothermal provinces, heat flow values $\left(\mathrm{mW} / \mathrm{m}^{2}\right.$ : in iralics) and geotherual gradients ${ }^{\circ} \mathrm{C} / \mathrm{km}$ ) I: Himalaya; II: Sohana; III: Cambay; IV: SONATA: V: West coast; VI: Godavari; VII: Mahanadi. M: Mehmadabad; B: Billimora.

Heat Flow Zones of Himalya Geothermal Province

Figure 4. Geothermal provinces and the Himalayan province map of Indian subcontinent [Ravi, 1996]

The investigations have identified several sites which are suitable for power generations as well as for direct use. It has been estimated that these provinces are capable of generating 10,600 MW of power [Ravi, 1996]. The first pilot Binary Cycle plant of $5 \mathrm{~kW}$ power using R113 organic fluid was successfully operated by the Geological Survey of India at Manikaran (HP), which proved the power producing capability of this province. The space heating experiments were also successfully conducted using thermal discharge by the Geological Survey of India. The seven geothermal provinces and the Himalaya province are shown in the picture (Figure-4).

The collision of the Indian plate with the Eurasian plate resulted in the formation of the Himalayas about 45 million years ago and as one of the largest geothermal belt, over 150 $\mathrm{Km}$ wide extends $3000 \mathrm{Km}$ through parts of India, Tibet, China, Myanmar and Thailand replete with more than 1,000 hot-spring areas. Over 150 of these areas are hot enough to generate electricity. The arc of volcanic islands incorporating the Coco Island (Burma), Nar-Condom Island (India), and Barren Island (India) is situated on the eastern tail end of Himalayan Geothermal Belt.

The year-wise data of the major earthquakes of Richter scale $(>4)$ in the peninsula and the associated geothermal provinces have been tabulated below from $1819 \mathrm{AD}$ to 2007 $\mathrm{AD}$ : 
Table 1. Earthquakes sponsored by the geothermal provinces of the Indian subcontinent

\begin{tabular}{|c|c|c|c|c|}
\hline Year & Region/Epicenter & Magnitude & Toll & $\begin{array}{l}\text { Name of Associated Geothermal } \\
\text { Province }\end{array}$ \\
\hline 1819 & Kutch, Gujrat & 8.0 & 2,000 & Cambay \\
\hline 1885 & Sopore, JK & 7.0 & 2,000 & Himalaya \\
\hline 1897 & Shilong & 8.7 & 1,542 & Himalaya \\
\hline 1905 & Kangra, HP & 8.0 & 19,500 & Himalaya \\
\hline 1918 & Assam & 7.6 & NA & Himalaya \\
\hline 1930 & Assam & 7.1 & NA & Himalaya \\
\hline 1934 & Bihar - Nepal & 8.3 & 10,700 & Himalaya \\
\hline 1941 & Andaman Island & 8.1 & NA & Himalaya \\
\hline 1943 & Assam & 7.2 & NA & Himalaya \\
\hline 1950 & Arunachal & 8.5 & 1,526 & Himalaya \\
\hline 1956 & Gujarat & 7.0 & 113 & Cambay \\
\hline 1960 & Delhi & 6 & Nil & Sohana \\
\hline 1967 & Koyna, Maha & 6.5 & 177 & West Coast \\
\hline 1970 & Bhadrachalam, AP & 6.5 & Not Known & Godavari \\
\hline 1970 & Broach, Gujrat & 5.7 & Not Known & Cambay \\
\hline 1975 & Himachal Pradesh & 6.5 & Not Known & Himalaya \\
\hline 1988 & Bihar-Nepal & 6.4 & 900 & Himalaya \\
\hline 1991 & Uttarkashi, UP & 6.6 & 2,000 & Himalaya \\
\hline 1993 & Latur, Maha & 6.3 & 9,748 & West Coast \\
\hline 1997 & Jabalpur, MP & 6.0 & 38 & SONATA \\
\hline 1999 & Chamoli, UP & 6.8 & 100 & Himalaya \\
\hline 2001 & Bhuj, Gujarat & 8.7 & 19,988 & Cambay \\
\hline 2004 & Andaman Island & 7.5 & 2,000 & Himalaya \\
\hline 2005 & Muzafarabad,JK & 8.5 & 36,000 & Himalaya \\
\hline 2007 & Bahadurgarh, HR & 4.3 & Nil & Sohana \\
\hline 2009 & Andeman Island & 7.7 & 26 & Himalaya \\
\hline 2011 & New Delhi & 4.2 & 0 & Sohana \\
\hline 2011 & Gangtok, Sikkam & 6.9 & 118 & Himalaya \\
\hline 2012 & Andeman Island & 6.2 & 0 & Himalaya \\
\hline 2013 & $\mathrm{~J} \& \mathrm{~K}$ & 5.8 & 2 & Himalaya \\
\hline 2014 & Andeman Island & 6.7 & 0 & Himalaya \\
\hline
\end{tabular}

From the above table it is quite evident that the epicenters of all the big damaging earthquakes of Indian region during last 200 years are strictly located in the jurisdiction of above mentioned seven geothermal provinces of India. This is a glaring fact in support of our hypothesis that earthquakes are the emission of surplus unmanaged geothermal energy accumulated in the respective geothermal provinces during last two centuries. On the other hand, the portion of the Gangetic Plains comprising of Kanpur, Allahabad and Varanasi situated in the vicinity of Himalayan plate boundary, but lying in non-geothermal province (a low heat flow region), has not witnessed any earthquake hazard in the last 3000 years. This shows failure of the influence of mechanical energy accumulation parameters i.e. strike-slip and stress-strain at plate boundary, and success of geothermal energy accumulation parameters like heat flow value beneath the surface. 


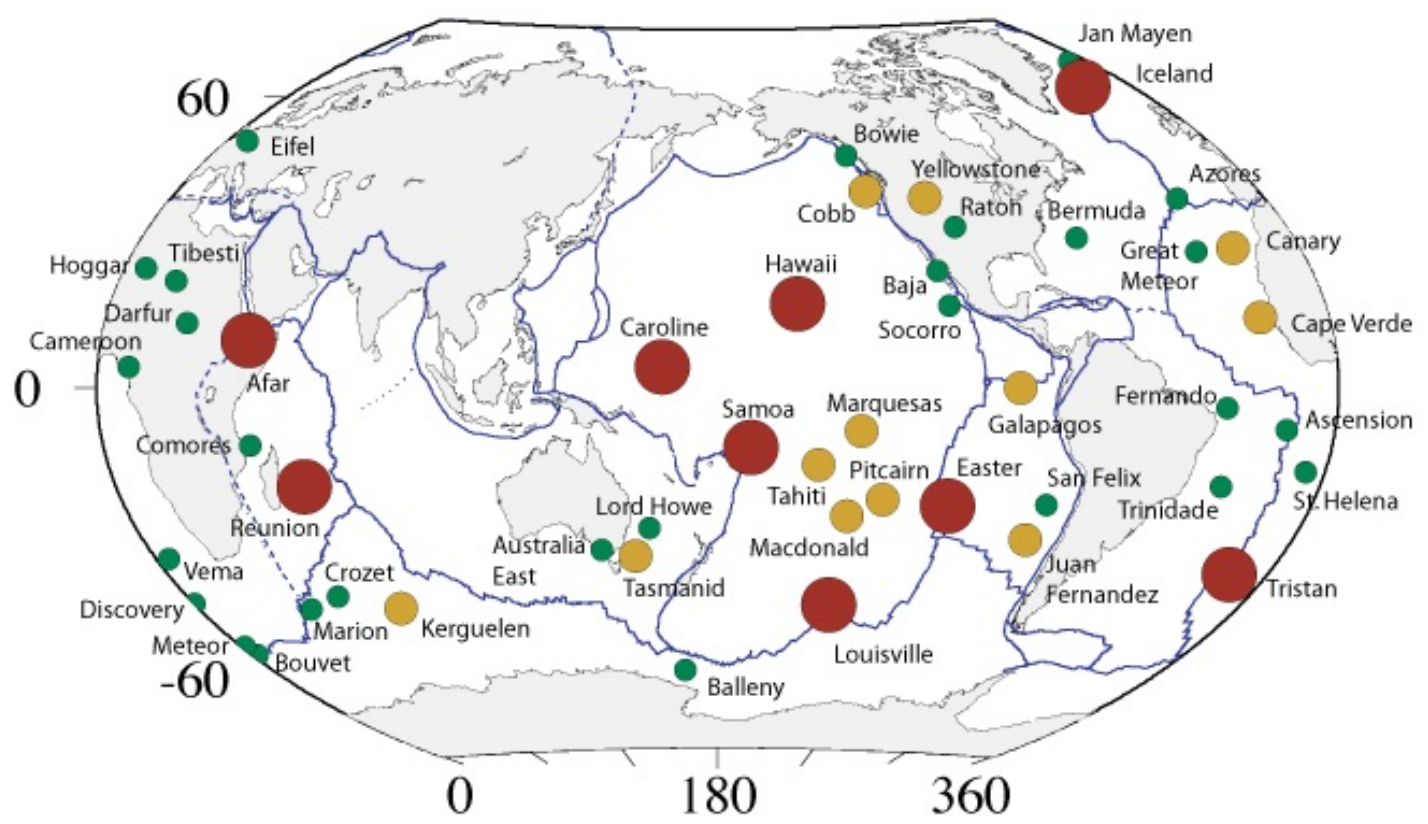

Figure 5. The Intra-plate hotspots: Large (red), Medium (yellow) and Small (green) [Foulger, 2010].

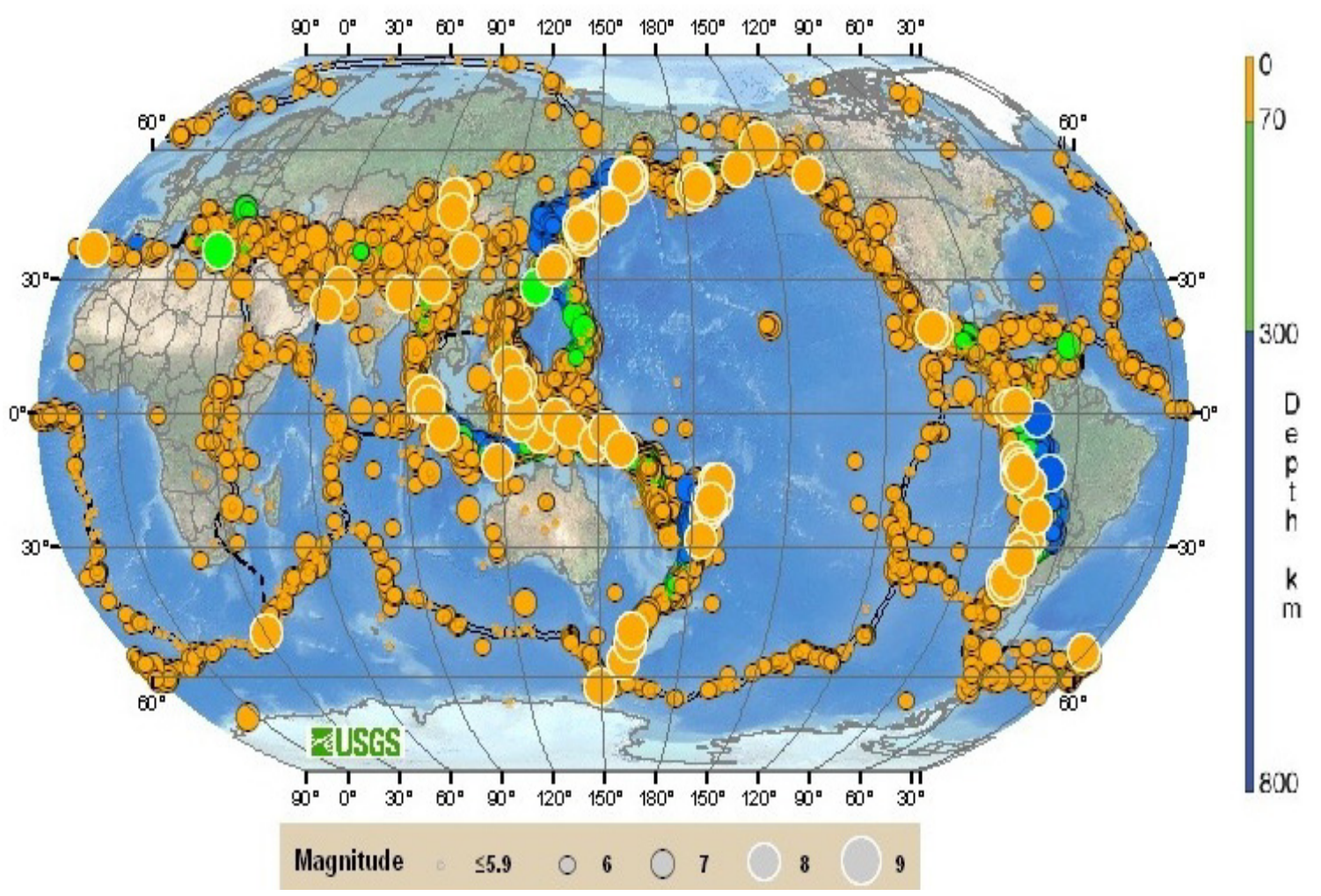

Figure 6. Major Earthquakes since 1900 [Courtesy: US Geological Survey]

\subsection{Intra-Plate Seismicity}

There are certain earthquake events which occurred quite far from the plate boundaries. In addition, there is a large number of hotspots and earthquakes far from the fault lines such as in Hawaii, Yellowstone, Caroline and Africa shown in the Figure 5 above; and divergent zones with unusually prolific volcanism such as seen in Iceland still do not fit well in the model of Plate Tectonics [Foulger,2010]. Such events are attributed to reactivation along the old faults called intra-plate faults.

The Mantle Plume hypothesis [Campbell, 2005 \& with Geoffrey, 2006] tries to explain such hotspots, and the trails of seamounts in the pacific fit well in this model. Moreover, the seismic tomography images show that most of the hotspots are concentrated on the two super plumes. Despite 
of a number of evidences this is not well accepted because many of its predictions have not been well accredited by geological or petrological observations. It seems clear that intra-plate volcanism and seismicity does imply the semi-rigid behavior of plates. We believe that the Plate Tectonics theory and Mantle Plume hypothesis go hand in hand and the entire geo-dynamism is fueled by the geothermal energy. So, it is the geothermal power that funds the intra-plate quakes and volcanism in the weak parts of the lithosphere.

In India, during 2000BC the Indus Valley civilization was spread over in the Sapta Sindhu (Saraswati, Indus, Ravi, Beas, Sutlej, Jhelam, and Chenab) area in North West. The recovery of melted and burnt remains from the site during excavation by archeologist stands testimony to the unique feature that this civilization was devastated by severe earthquakes $[G S A, 2010]$. Examples of the earthquake effects are present in Banbhore in the Indus Delta, Brahmanabad, and the Harappa sites of Kalibangan and Dholavira. As per our hypothesis those earthquakes were triggered by a moderate magmatic extrusion resulting from excess geothermal energy pressure accumulated beneath Sohana geothermal province. This was a blatant case of intra-plate seismicity in ancient India.

A swarm of mild earthquakes have been rattling the North West India comprising of Delhi, Haryana, Rajasthan and Punjab. The frequency of micro-seismicity has increased alarmingly. For the past few years, an 'earthquake swarm' has been reported from the southern Punjab basin with its epicenter near the town of Jind of Haryana. Apart from Jind, tremors were also felt in nearby areas of Kaithal, Narnaul and Hissar districts: rattling of doors, windows, shop shutters, shaking of furniture and cracks in the walls have been reported. The recent earthquake dated $26^{\text {th }}$ November, 2007 having epicenter at Bahadurgarh (Delhi, Haryana Border) measuring 4.3 degree on Richter scale has sufficiently scared Delhiites and pricked their vanity. This was the fourth consecutive earthquake in year 2007 having epicenter at Bahadurgarh; again an event of mid-plate seismicity.

In addition to this the earthquakes of very high magnitude reported in the Western and South Indian districts like Bhuj, Jabalpur, Latur \& Bhadrachalam are vivid examples of the intra-plate seismicity and geothermal origin of these events.

\section{Harnessing Geothermal Energy}

Geothermal energy is the immense store of heat $\left(\sim 10^{13} \mathrm{~J}\right)$ in the earth, which alone would take over $10^{9}$ years to exhaust [Ryback and Mongillo, 2006]. So the geothermal source is an extremely large and self sustained natural gift. The current power rates are more than double humanity's current energy consumption from all primary sources, most of which are not recoverable. As per the recent international market overview by Geothermal Energy Association (GEA)
11,765 MW of (gross) geothermal power are operating globally in addition to several hundred MW in the final stages of construction as of August 2013. By the end of 2013 the global geothermal market is expected to reach 12,000 MW of geothermal capacity. Currently, there is 11,766 MW planned capacity additions of geothermal power in the early stages of development or under construction in 70 countries and territories around the world. Additionally, developers are actively engaged with $27 \mathrm{GW}$ of geothermal resource globally.

USA is the world's largest producer of geothermal electricity. The first geothermal plant opened at 'The Big Geysers' in California in 1960 continues to operate successfully. The California Energy Commission (CEC) is running this largest geothermal energy plant of $1800 \mathrm{MW}$. We are citing the encouraging results at page 19 of the CEC report [CEC Report, 2004]: "If one considers the energy release over time, rather than just a count of earthquakes, then one gets a different picture. We took the same information in Figure 4 from 1984 to the present and looked at the energy release over time by using an energy magnitude relation $\log 10 \mathrm{E}=11.4+1.5 \mathrm{M},(\mathrm{E}=$ energy in Ergs, $M=$ magnitude of the event). Figure 7 shows the rate of seismicity (total events above $\mathrm{M}=1.5$ ) for the Geysers area since 1984, If one converts the magnitudes to energy one obtains the results in Figure 7, As can be seen the rate of energy release is actually decreasing as a function of time" .

The decreasing rate of energy release in the above figure reflects optimism about the high magnitude earthquake hazard free future of the Geysers Area. Harnessing geothermal energy is multifold rewarding. Besides fulfilling the electricity requirement of 10,00,000 household units of North California in an Eco friendly manner; page 20 of the report further states: "To date there has been no faults mapped in The Geysers which would generate a magnitude of 5.0 or greater. This is not an absolute guarantee that one would not happen, but does lower the likelihood".

The largest earthquake ever detected in The Geysers area measured 4.6 on the Richter scale; while seismic activity elsewhere in the region can be much more dangerous. In 1969, Santa Rosa, California, 40 miles from the geothermal site, experienced an earthquake of magnitude 5.7. The experts do not treat the seismic activity at The Geysers as a significant concern compared to the larger-magnitude seismicity in the region, and therefore put specifically no focus on monitoring efforts in the Geysers field. As per the Enhanced Geothermal System (EGS) Project Report $\left(1^{\text {st }}\right.$ Sept. 2011 to $5^{\text {th }}$ March 2013) the seismic event frequency tends to decrease with continued injection at a constant flow rate. The project located in Basel, Switzerland, was also deemed too dangerous and capable of triggering earthquakes. The project has been on hold since 2006, when it caused a 3.4 magnitude earthquake, thousands of aftershocks and millions worth of damage in Basel, a town of about 1, 67, 000 people. 


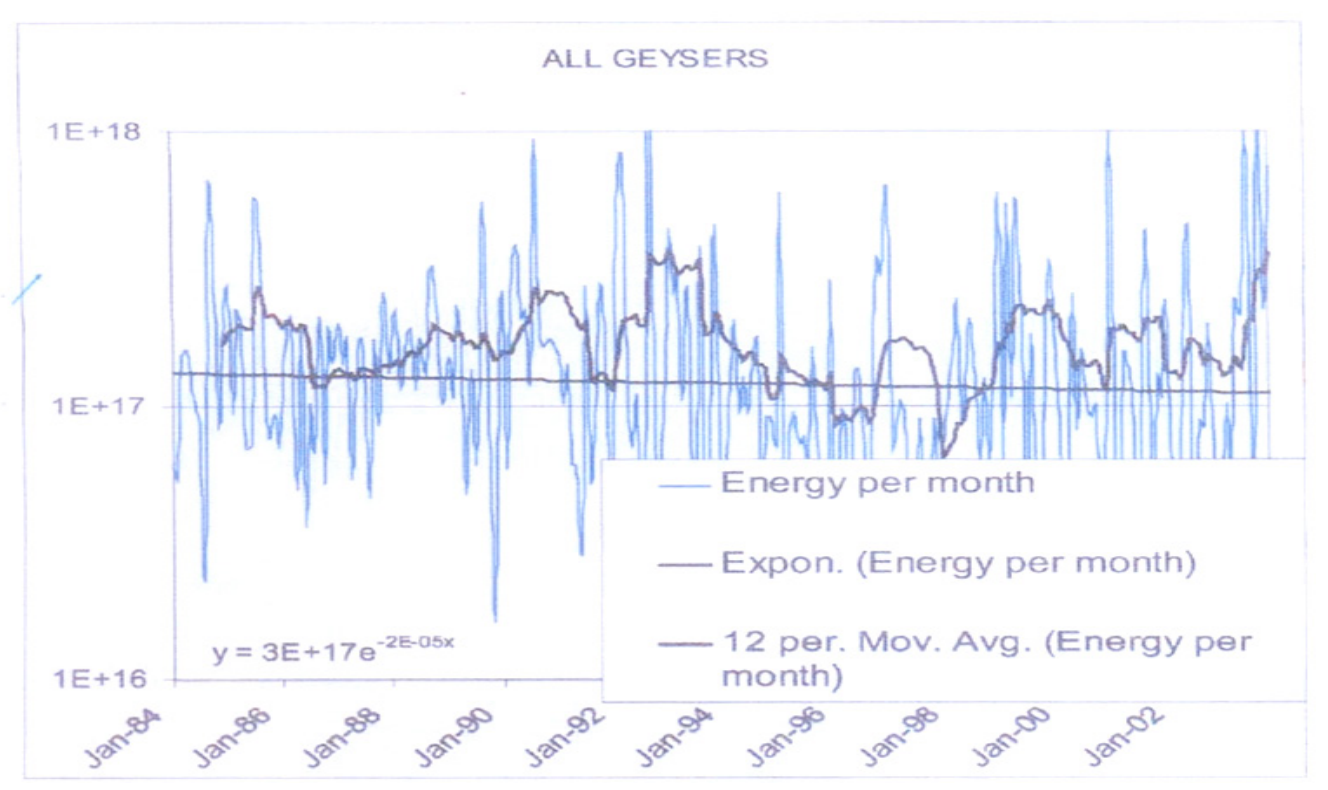

Figure 7. Energy release through the power plant 'the Geysers' [CEC Report, 2004]

It may be noted that in the EGS, the bedrock is fractured by blasting and high pressure water is circulated through the cracks to heat it and produce steam that powered the turbines of a power plant. It is not surprising that in the fracturing process, the high pressure water blow into the bores can cause earthquakes, because the water entering into the cracks produce steam of very high pressure i.e. super-steam and do not find an immediate exit except the one used for power generation. The excess steam enters into the nearby area through cracks and cause earthquake. In addition, naturally, both projects were also based in areas with a history of seismic activity. So rather discouraging the harnessing of geothermal energy there is a need to continue the R \& D and stay most likely with the natural hot-springs area and wait for the next technological advancement in the EGS.

It has been found that the geothermal field development and expansion has resulted in seismic activity, though many of these induced micro-earthquakes require sensitive instrumentation to be detected. The Environment Impact Report (EIR) determined that a geothermal facility would induce less than significant increases in seismic activity [Alyssa et al, 2007].

It is true that at present about $12000 \mathrm{MW}$ as electricity is being harnessed and this is a tiny share of the total heat production rate inside the earth $(44.2 \mathrm{TW})$, but the fraction of heat energy responsible for the earthquake is also too small i.e. $\sim 0.01 \%$ [William, 1997]. As we argued it is the surplus amount of internal heat pressure that is released by funding the plate movements, point fracture/ rupture along the active fault and intra-plate regions. After penetrating, piercing, puncturing and punching through the surface of earth this energy emerges out and enters into open space. Therefore to reduce the intensity of earthquake significantly we need to play with the $\sim 0.01 \%$ of the heat.

In the light of the above results from 'the Big Geysers' of California if we harness this excess heat flow pressure through the active fault lines or geothermal provinces, we can minimize the risk and hazard of the impending earthquakes. That is, the intensity of the prospective earthquake can substantially be reduced. Moreover, we get electricity as a bonus.

\section{Discussions and Conclusions}

About 500,000 earthquakes occur each year which are detectable with current instrumentation and around 100,000 of these can be felt. Minor earthquakes occur nearly constantly around the globe and major earthquakes occur less frequently, but in the identified pockets. The actual cause of the continental drift i.e. motion of the plates is not clear yet, it is however interesting that the tectonic activity - the volcanic eruptions---has also been discovered in some other planets and satellites. This shows a similar kind of processes going on in interior of those bodies [Byalko, 1987]. The researchers of Utah University [Hasterok and Chapman, 2007] have shown that the heat inside the planet accounts for half the reason land rises above the sea level or higher to form mountains. It is the pressure of created by the heat that makes rock in the continental crust and upper mantle expand to become less dense and more buoyant.

The plate tectonics theory fails to explain vividly a wide range of earthquake events as discussed in Section 2. In our investigation we found quite convincing overlaps in the earthquake events, seismic zones, heat flow profile and geothermal provinces in the Indian peninsula. We reached to a conclusion and proposed a hypothesis that in the root it is the geothermal energy which gives rise to plate movements, inter-plate and the intra-plate earthquake events. The excess pressure of the geothermal power punctures and pierces the physically weaker section along the fault lines and even mid part of the plates. 
We support our hypothesis with the facts and figures of the heat flow data and earthquake events discussed above in detail. In addition to that the deep-focus earthquakes having hypocenter as deep as $700 \mathrm{Kms}$ are questionable whereas the thickness of lithosphere plates is merely $70-100 \mathrm{Kms}$. The occurrence of such earthquakes cannot be explained in terms of release of accumulation of stress and strain i.e. strike-slip along the plate boundaries of lithosphere. So, these earthquakes cannot be dubbed as mechanical energy release events. It is believed that metamorphic fluids released from subducting plate causes melting in the surrounding asthenosphere. Magma is released and intrudes into the overlying lithosphere accounts for volcanic activity, earthquakes, high heat flow, and high temperature metamorphism. Obviously, these volatile explosions are on account of melting $\&$ boiling of subduction plate fragments i.e. the events generated by the effect of geothermal energy.

It is thought to be virtually impossible to control the course of natural events, but on the basis of our findings and the California Geysers report we are pretty sure to put forward such a bold statement that harnessing the geothermal energy as house heating and electricity generation can reduce the impact of earthquakes, tsunamis, volcanism and hot-springs. So, in order to cope with the escalating energy crisis and as the measure of Earthquake Disaster Management there is dire need of harnessing the surplus pressure amount of geothermal power as direct use and electricity generation at least in selected pockets of natural geothermal provinces. Furthermore, an Investment Bank report says that this energy is cheaper than the coal driven power [Christopher, 2009]. Harnessing this energy must be promoted as it is cost effective and environmentally clean. To get the quake risk free geo-power using the EGS, we will still have to wait for a higher technology.

The results and the inferences drawn in this work are quite general and not only pertaining to the Indian subcontinent. The earth is spherically symmetric by construction and the structure of the upper mantle layer and lithosphere is quite similar throughout the globe. So the conclusions drawn are equally applicable to the entire geo-dynamics subject to the nature of fault lines. In this hypothesis we do not refute, challenge or contradict the Plate Tectonics theory, Mantle Plume and Plate Model hypothesis, rather we provide a solid base and better explanation to the volcanism, hotspot, hot-spring and earthquake dynamics.

Noble gases, being chemically inert, are excellent natural tracers for several geological features. Radon $\left({ }^{222} R a\right)$ is the product of the uranium decay series and its spatial variation is widely applied in studies to locate buried/ blind faults and in seismic monitoring activities. Efforts have been made to elucidate the role of ${ }^{222} R a$ gas to delineate active faults and their relationship to seismically active areas. In recent studies [Sunil et al, 2012], it has been found that the radon concentration varies not only with tectonic feature, but also with the change in lithology. We believe that the study of the spatial distribution of the radon content i.e. radon profile of soil gas in the geothermal and seismically active regions may help us with the prediction of impending earthquake and conclusion about the geothermal origin of earthquakes.

\section{Acknowledgements}

Figures and Graphs in the paper have been acknowledged there and then by using the appropriate citations. One of the authors, B. C. Chauhan, is thankful to the Inter University Centre for Astronomy \& Astrophysics (IUCAA) for providing necessary facilities during the completion of this work.

\section{REFERENCES}

[1] Alfè D. et al, Philosophical Transactions of the Royal Society 360, p1227, 1795.

[2] Alyssa K., Diana B. \& Karl G. "A guide to geothermal energy and the environment (2007)" Geothermal Energy Association, 209 Pennsylvania Avenue SE, Washington, D.C. 20003.

[3] Byalko, A.V., Our Planet: The Earth; Mir Publishers, 1987.

[4] California Energy Commission (CEC) Final Report, "Integrated High Resolution Micro- earthquake Analysis and Monitoring for Optimizing Steam Production at The Geysers Geothermal Field, California, 2004." http://quake geo.berkelev.edu

[5] Campbell, I.H., Elements 1, p265, 2005; Ian H. Campbell and Geoffrey F. Davies, Episodes 29, 3, p162, 2006.

[6] Christopher M., Scientific American 55, 2009.

[7] Christopher H. S., Nature 391, p37, 1 January 1998.

[8] Editorial, Nature, "Quake after-effects", (Geoscience) 6, p585, August 2013.

[9] Edward J. T. and Frederick K. L., Earth: An Introduction to Physical Geology,

[10] Prentice Hall Inc., New Jersey, 1996.

[11] Foulger G.R., "Plates vs Plumes: A Geological Controversy", Wiley-Blackwell, 2010; ISBN 978-1-4051-6148-0.

[12] Geological Society of America (GSA) Special Papers 471, p119, 2010, "Earthquakes and civilizations of the Indus Valley: A challenge for archaeo-seismology".

[13] Geological Survey of India (GSI): Geothermal Atlas of India (GAI) 1987 \& 1991

[14] Hasterok, D and Chapman, D.S., "Continental Thermal Isostacy: 2 Applications to North America”, J. Geophys. Res., 112, B06415, 2007.

[15] KamLAND Collaboration, Nature Geoscience 4, p647, 2011.

[16] Marvin H. J., Journal of Geomag. and Geoelectr. 45, p423, 1993; Current Science 93, no. 11, p1485, 2007.

[17] National Earthquake Information Centre (NEIC), 17th Oct. 2005; M7.5 Northern Peru Earthquake on 26th Sept. 2005. 
[18] Pollack H. N., Hurter S. J. and Johnson J. R., Reviews of Geophysics 31 (3): p267, 1993.

[19] Ravi S., Geo. Surv. of India, Spec. Pub. 45, p1, 1996.

[20] Rybach, L. and Mongillo, M., GRC Transactions 30, p1083, 2006.

[21] Sunil S. et al, Advances in Appl. Sc. Research 3(5), p3060,
2012.

[22] William Lowrie, "Fundamentals of Geophysics", p179, Cambridge University Press, 1997.

[23] World Congress on Natural Disaster Mitigation (WCNDM) Proceedings, organized by Institution of Engineers (India) 19-22 February 2004. 